International Journal of Current Advanced Research

ISSN: O: 2319-6475, ISSN: P: 2319 - 6505, Impact Factor: SJIF: 5.995

Available Online at www.journalijcar.org

Volume 6; Issue 3; March 2017; Page No. 2707-2710

DOI: http://dx.doi.org/10.24327/ijcar.2017.2710.0083

CASE REPORT

\title{
AWARENESS OF ORAL CANCER AMONG NON MEDICAL STUDENTS: A SURVEY
}

\author{
Sri Vasavi Kadiyala and Gifrina jayaraj
}

Saveetha Dental College, Saveetha University, Chennai

A R T I C L E I N F O

Article History:

Received $8^{\text {th }}$ December, 2016

Received in revised form $16^{\text {th }}$ January, 2017

Accepted $14^{\text {th }}$ February, 2017

Published online $28^{\text {th }}$ March, 2017

\begin{abstract}
A B S T R A C T
Objective: To know the awareness of oral cancer and their attitude and habits of tobacco use among non-medical students.
\end{abstract}

Methods: The present survey was carried out from 1st December to 30 December, 2016 in non medical universities of chennai. The study population included students ranging from 19 to 25 years of age who had no background knowledge of medicine and were not related to any branch of the medical sciences. A total of 100 students were randomly selected in this study. The information was gathered by asking questions using a well structured questionnaire covering aspects regarding knowledge about oral cancer, causative factors of oral cancer, dental attitude of the patients. The questionnaire was explained to the students completely prior to handing it out to them. Study protocol and the use of data for research was fully explained to the students to get fully informed and understood content. The data collected was analysed by using Microsoft Excel 2007.

Results: In this study $60 \%$ students were males and $40 \%$ were females. $84 \%$ of students were familiar with the word oral cancer, $42 \%$ of students were aware that cigarette can cause oral cancer while $33 \%$ stated snuff dipping as cause of oral cancer. $45 \%$ students thought lump is the sign of oral cancer. With regards to frequency of visiting a dentist $55 \%$ said that they will visit a dentist in trouble.

Conclusion: Educated population of this region are unaware mainly about risk factors. $22 \%$ students had misconception that dental fillings cause oral cancer. $43 \%$ of students think that oral cancer is communicable. This affects the cancer patient psychologically. $55 \%$ of students visit the dentist only when they are in pain.

So it is important that routine visits of people is necessary as prevention is better than cure. This study showed that the educated population of this region is unaware of basic knowledge about oral cancer especially about its signs and symptoms.

Copyright $\bigcirc 2017$ Sri Vasavi Kadiyala and Gifrina jayaraj. This is an open access article distributed under the Creative Commons Attribution License, which permits unrestricted use, distribution, and reproduction in any medium, provided the original work is properly cited.

\section{INTRODUCTION}

Oral cancer is the 6 most commonly reported malignancy worldwide.(1) Although many types of cancer occur in oral cavity, about $90 \%$ of these are squamous cell carcinomas.(2) Out of the many factors associated with oral cancer, tobacco usage has been identified as the strongest.(3) Oral cancer is becoming a major health concern because of the recent rise in its incidence especially in underdeveloped countries. According to worldwide statistics an estimated 263900 new cases were found with 128000 deaths annually worldwide.(4) About 58\% cases of oral cancer occur in south and south east Asia.(5) Likewise the condition in India is far worse, according to statistics by WHO(GLOBOCAN 2008) overall oral cancer is second most commonest disease in India with deaths occurring annually. Inspite of the increased mortality and morbidity oral cancer remains may have a better prognosis if it's detected at an early stage.

*Corresponding author: Sri Vasavi Kadiyala

Saveetha Dental College, Saveetha University, Chennai
Thus awareness from signs of oral cancer and knowledge about its causative factors is very important as majority of the public still remains unaware of basic knowledge about oral cancer.(6)

\section{MATERIALS AND METHODS}

The present survey was carried out from 1st December to 30 December, 2016 in non medical universities of chennai. The study population included students ranging from 19 to 25 years of age who had no background knowledge of medicine and were not related to any branch of the medical sciences. A total of 100 students were randomly selected in this study. The information was gathered by asking questions using a well structured questionnaire (fig 1) covering aspects regarding knowledge about oral cancer, causative factors of oral cancer, dental attitude of the patients. The questionnaire was explained to the students completely prior to handing it out to them. Study protocol and the use of data for research was fully explained to the students to get fully informed and understood content. The data collected was analyzed by using Microsoft Excel 2007. 
Awareness of oral cancer among non medical students: A survey

1. Wrat is the type of cancer most ocinmonly hasd?

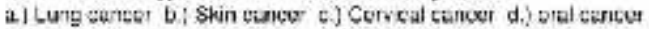

2. Arc pau fistil ar with werd oxal eancot.

a) Yes b) Yo

3. Whet are the risk fectors icr oral carcer

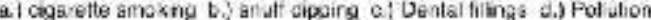

6.1 Chinkng

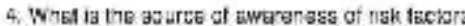

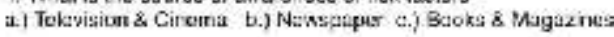

5. Wint are the signis of ural casicer

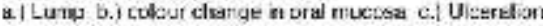

8. Do you think oral carsar is communcalla

Q1 Yes B.I No

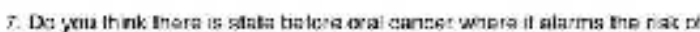

aral cancoser

a.) Yes b.) Na

Q. De you think oral cancer is curstike

a.) Yes a.) Na

2. Do , wu thnk oral cancer cen sceur st en young age

Q1 ves ano

10. Do you think the sebow conditicns if byrored can laat to carxer

a) Chronic irritation tom a sang woth b.) Denturas

11. What dh you th nk that comeds you wo vieg a derte-

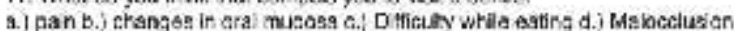

Q.j Niesing teeth

Fig. 1

\section{RESULTS}

Out of 100 students questioned $60 \%$ were males and $40 \%$ were females. In response to type of cancer most commonly heard of, $37 \%$ of college students were familiar with lung cancer, $32 \%$ skin cancer and $15 \%$ cervical cancer while only $16 \%$ knew the word oral cancer. (fig 2)

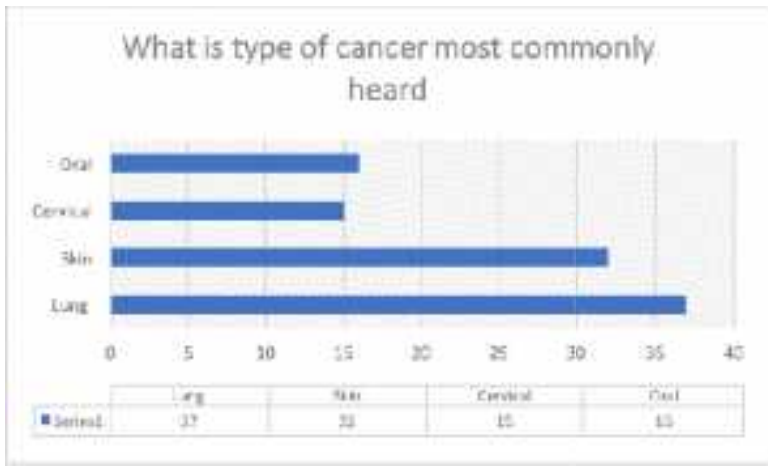

Fig.2

About $84 \%$ students are familiar with term oral cancer where as $16 \%$ were not. (Fig 3)

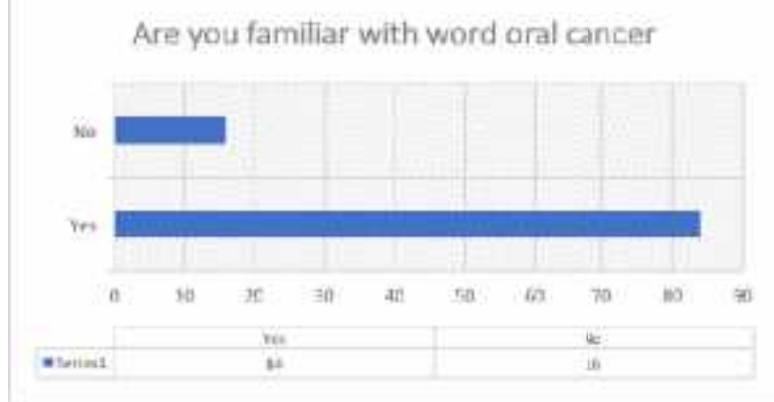

Fig. 3
Regarding risk factors for oral cancer $41 \%$ students answered cigarette smoking, 30\% snuff dipping, $22 \%$ dental fillings, $3 \%$ pollution, while $4 \%$ identified drinking to be linked with oral cancer. (fig 4)

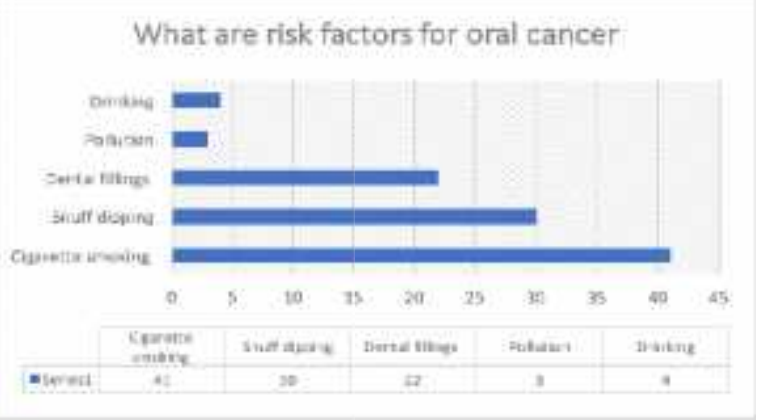

Fig. 4

About source of awareness of risk factors for oral cancer $74 \%$ students answer books \& magazines, while 16\% news paper. (fig 5)

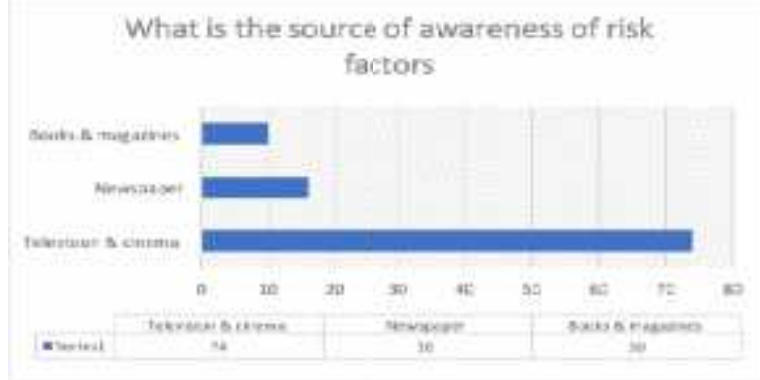

Fig. 5

About $45 \%$ thought lump, $31 \%$ color change in oral mucosa while $24 \%$ said an ulcer could be the early sign of oral cancer. (fig 6)

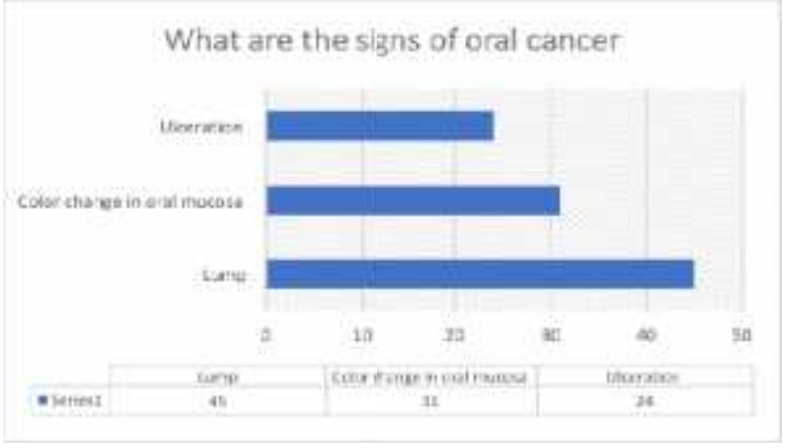

Fig. 6

About $43 \%$ students thought oral cancer is communicable where as $\mathbf{5 7 \%}$ students thought it wasn't.(fig 7)

\section{Do you think oral cancer is communicable}

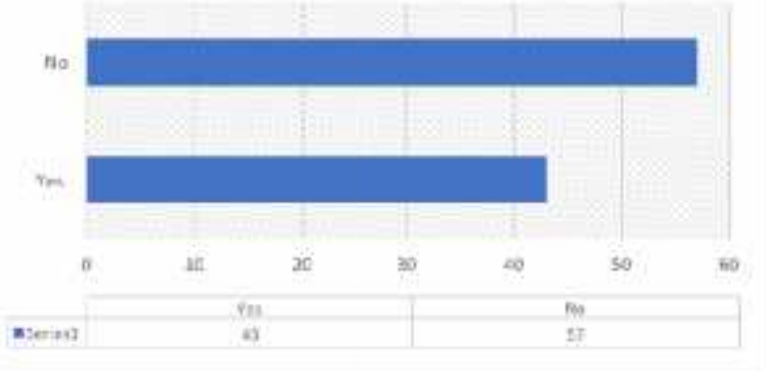

Fig 7 
About $71 \%$ students thought there is state before oral cancer where it alarms the risk while $29 \%$ didn't think so.(fig 8 )

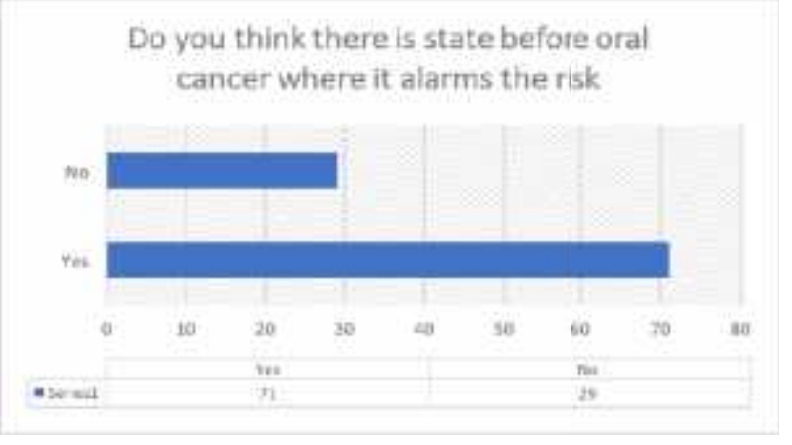

Fig 8

About $59 \%$ students thought that oral cancer is curable while $41 \%$ thought it is not curable. (fig 9)

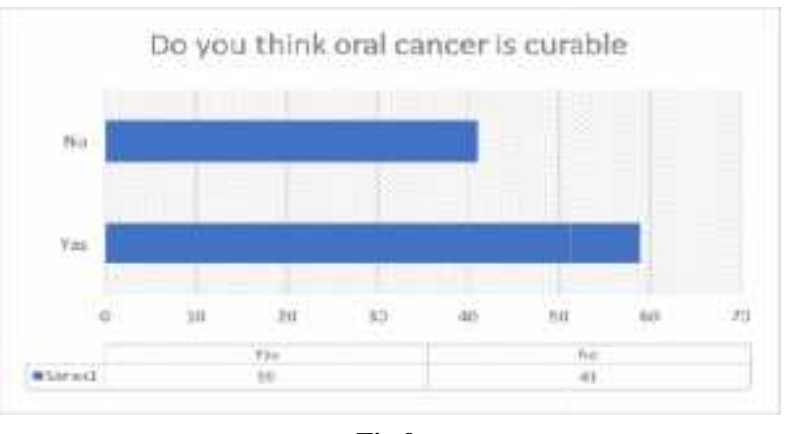

Fig 9

About $69 \%$ students thought oral cancer can occur at young age while $32 \%$ didn't think so. (fig 10)

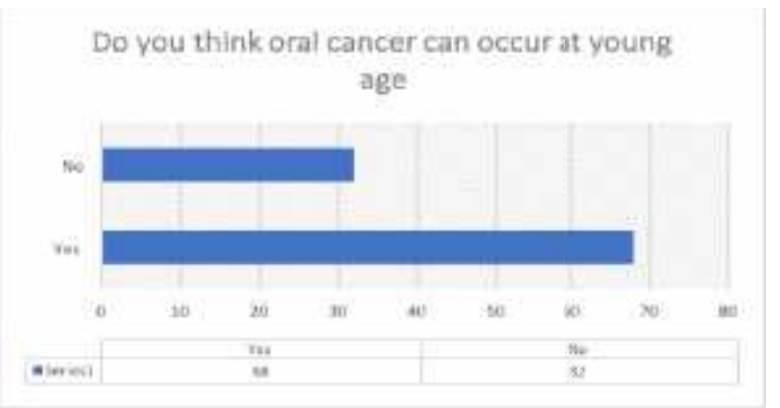

Fig 10

About $67 \%$ students answered chronic irritation from sharp tooth if ignored can lead to cancer while $33 \%$ students thought denture. (fig 11)

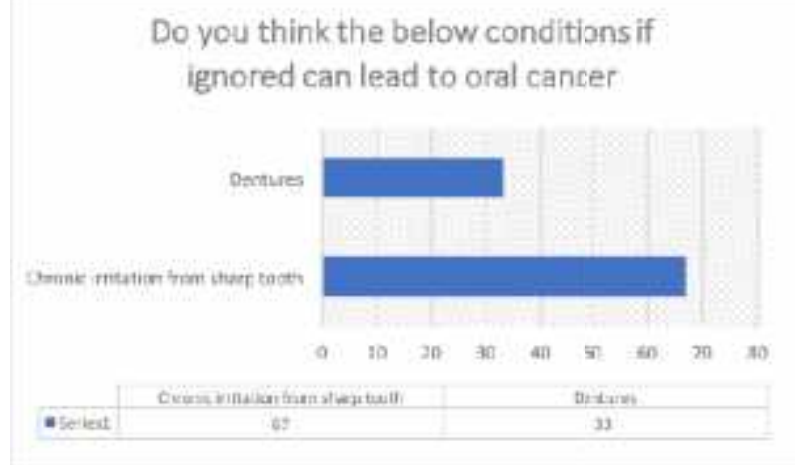

Fig 11

Regarding dental attitude and attendance $55 \%$ of students would visit a dentist only when in trouble \& stated pain as the main reason for dental visit, $23 \%$ because of changes in oral mucosa, $13 \%$ for difficulty in eating, $4 \%$ because of malocclusion, $5 \%$ b cause of missing tooth.(fig 12)

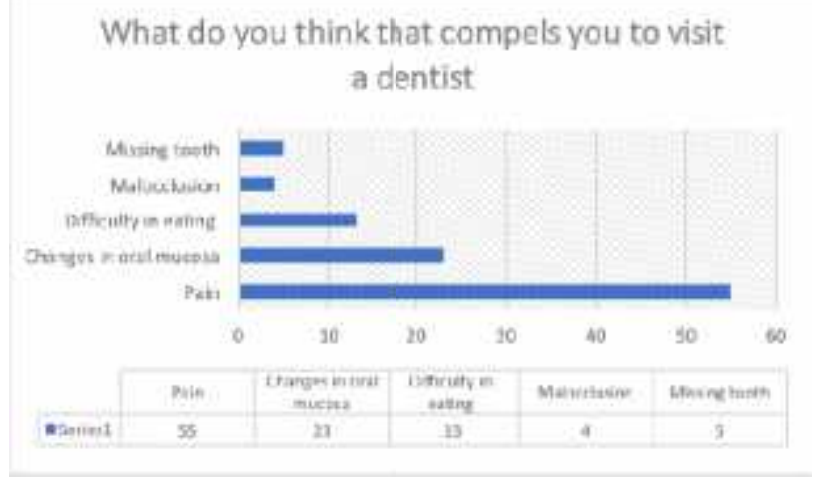

Fig 12

\section{DISCUSSION}

In the present study it was found only $16 \%$ of students were familiar with oral cancer, while $15 \%$ were familiar with cervical cancer. This is in agreement with studies done by Warnakulasuriya (7)and Rogers (8) where less number of people were aware with the term oral cancer \& cervical cancer. However in another survey done in Britain in 2006 during oral cancer awareness week there was an improvement in peoples knowledge about oral cancer, may be due to increased media attention given to oral cancer during awareness week.(9) The low familiarity among the present population indicates the lack of Oral cancer awareness among the youngsters.

With regards to knowledge about risk factors of oral cancer, $71 \%$ of students identified smoking and snuff dipping to be associated with oral cancer there were also $22 \%$ who thought dental fillings caused oral cancer. This is in accordance with a study done in USA where $67 \%$ of adults could identify tobacco use to be linked with oral cancer.(10) Similarly in a study done in UK $90 \%$ of respondents thought smoking caused oral cancer.(11) Also in a study carried out in Germany more than half of responders could identify link between oral cancer and tobacco.(12) This may be due to the fact that this study was carried out among educated population and as such most of them were aware of tobacco as to be a cause for oral cancer. $22 \%$ students had misconception that dental fillings cause oral cancer. Results of the present study are in contrast to the studies done in Iran (13) and Srilanka (14) where less number of people were aware of risk factors for oral cancer. This may be due to the fact that these studies were carried among patients in hospital settings as compared to the student population in the present study.

Students were not aware of the key signs of oral cancer. In regards to the signs of oral cancer $24 \%$ thought a long standing non healing ulcer could be indicative of malignancy. These results are in accordance with study done in Florida where one half of adult population did not think red patches or bleeding could indicate oral cancer.(15) However the results are contradictory to studies carried out in North Carolina (16) and Turkey (17) where majority of population were unaware of oral cancer signs.(18) Reason may be due to the fact that organizational efforts and policies on government level 
are active in the west due to which an increased level of awareness especially regarding signs is seen. This is an important observation since lack of self detection by the patient particularly in early stages of disease leads to delay in diagnosis thus increasing the mortality and morbidity rate.(19) Still many people are ignorant of other signs of oral cancer like erythroplakia or swelling or any other precancerous state.

When students were asked about the frequency of visit to the dentist, $45 \%$ of students answered that they would visit dentist only when in trouble. Furthermore 55\% of students stated pain as the main reason for dental visit while only $23 \%$ would go to a dentist when they have an ulcer. This is in accordance to a study in Saudi Arabia where pain was stated as main reason for dental visits.(20) This may be due to the fact that knowledge regarding proper oral health and the need for oral examination is lacking in their population. This is a significant observation since it shows that even in the educated population of this region is unaware of the importance of regular dental examination. This point was also highlighted in a study done in USA where it was found that less than one third of the adult population had a proper cancer examination in the past.(21)

\section{CONCLUSION}

Educated population of this region are unaware mainly about risk factors. $22 \%$ students had misconception that dental fillings cause oral cancer. $43 \%$ of students think that oral cancer is communicable. This affects the cancer patient psychologically. $55 \%$ of students visit the dentist only when they are in pain.

So it is important that routine visits of people is necessary as prevention is better than cure.

This study showed that the educated population of this region is unaware of basic knowledge about oral cancer especially about its signs and symptoms.

\section{Acknowledgement}

The authors are thankful to the participants of the study, who co operated in the completion of the work.

\section{References}

1. Parkin D, PisaniP, Ferloy J (1999). Estimates of worldwide incidence of 25 major cancers in 1990. Int J Ca 80:827-841.

2. Cawson R A, Odell E W.Oral Cancer (2008). Cawson's Essentials of Oral Pathology and th Oral Medicine. 8 Edition; Churchill Livingston Elsevier: 277-290.

3. Johnson N: Tobacco use and Oral Cancer (2001): A Global Perspective. JDE : 65(4):324329.

4. Jemal A, Brey F, Center MM et al (2011). Global cancer statistics. CA: A Cancer Journal for Clinicians 61:69-90.

5. Nair U, Bartsch H, Nair J(2004). Alert for an epidemic of oral cancerdue to use of betal quid substitutesghutka and panmasala; A review of agents and causative mechanisms. Mutagenesis 19:251-262.
6. Farlay J, Bray J, PisaniP, et al. Globocan 2008; Cancerincidence, mortality and Jident Issue 1 VOLUME 1 OCTOBER 2012 prevalence world wide. IARC Cancerbase no.5 version2.0.Lyan; IARC Press:2004.

7. WHO Report (1984). Control of oral cancer in developing countries. Bulletin World Health Organisation 62: 817-830.

8. Horowitz AM, Goodman HS, Yellowitz JA et al (1996). The need for health promotion in oral cancer prevention and early detection. $J$ of Public Health Dentistry 56:319-330.

9. Warnakulasuriya KAAS, Harris CK, Scarrot DM et al (1999). An alarmin lack of pubic awareness towards oral cancer. BDJ 187:319-322.

10. Rogers SN, Rosemary H Lowe D (2011). Awareness of oral cancer in the Mersey Region. BJOMS 49:176181.

11. West R, Aikhatib MN, Mcneil A et al (2006). Awareness of mouth cancer in Great Britain BDJ 200:167-169.

12. Horrowitz AM, Nourjah P, Gift HC et al (1995). US adult knowledge of risk factors and signs of oral cancer 1990. JADA 126:39-45.

13. Redeker C, Wardle.J, Wilder.D et al(2009).The launch of cancer research UK's 'Reduce the risk campaign'.Baseline measurements of public awareness of cancer risk factors in 2004. European J of cancer 45:827-36.

14. Hertrampt k, Wens HJ, Koller M, et al (2010). Comparing dentist's and public awareness of cancer risk factors in a community based study in Northern Germany. $J$ of craniomaxillofacial surgery $: 1-5$.

15. Pakfetrat A, Falaki F, Esmaily HO, et al. Oral cancer knowledge among patients referred to Mashad dental school Iran. Archives of Iranian Medicine:13(6):54348.

16. Ariyavardhana A, VithanaarachchiN.Awareness of oral cancer and pre canceramong patients attending a hospital in Srilanka. Asian Pacific $J$ of Cancer Prevention6:58-61.

17. Tomar SL, Logan HL (2005). Florida adults oral cancer knowledge and examination experiences. J Public Health Dent 65(4):221230.

18. Patton LL, Agans R, Elter JR et al (2004). Oral cancer knowledge and examination experiences among north Carolina adults. J Public Health Dent 64(3):173-180.

19. Peker I, Alkurt MT (2010). Public awareness level of oral cancer in a group of dental patients. J Contemp Dental Practice 11(2):4956.

20. Adlard. JW, Hume MJ (2003). Cancer knowledge of general public in the UK: Survey in a primary care setting and review of literature. Clinical Oncology 15:174-80.

21. Mignogna MD, Fedele S, Russo LL(2004). The world cancerreport and burden of oral cancer. European J of Cancerprevention 13(4):13942. 